\title{
PREDICTION OF THE WORK-RELATED INJURIES BASED ON NEURAL NETWORKS
}

doi: $10.2478 /$ czoto-2021-0003

Date of submission of the article to the Editor: 10/12/2020

Date of acceptance of the article by the Editor: 2/02/2021

\author{
Jelena Ivaz ${ }^{1}$ - orcid id: 0000-0001-9263-6804 \\ Ružica R. Nikolić ${ }^{2}$ - orcid id: 0000-0003-3042-8916 \\ Dejan Petrović ${ }^{1}$ - orcid id: 0000-0001-8588-2046 \\ Jelena M. Djoković1 - orcid id: 0000-0001-5542-8088 \\ Branislav Hadzima ${ }^{2}$ - orcid id: 0000-0002-8201-905X \\ ${ }^{1}$ Technical Faculty of Bor, University of Belgrade, Serbia \\ ${ }^{2}$ Research Center, University of Žilina, Slovakia
}

\begin{abstract}
Artificial neural networks (ANN) are a powerful tool in the decision-making process, especially in solving the complex problems with a large number of input data. The possibility to predict the work-related injuries in the underground coal mines, based on application of the neural networks, is analyzed in this work. the input data for the network were obtained based on a survey of 1300 respondents. After analyzing the input data influence on the network output, 14 most influential inputs were selected, with help of which the network correctly predicted whether the worker would suffer the work-related injury or not, with $80 \%$ precision. The two models were developed, based on the multilayer perceptron (MLP) and radial basis function (RBF) networks. The two models' results were compared to each other. The sensitivity analysis was used to select the most influential parameters, like mine, age of miners, as well as their work experience. The parameters were further analyzed by use of the descriptive statistics. The selected parameters are direct indicators of problems that can cause injuries. The obtained results point to the fact that the work-related injuries can be successfully predicted by application of the artificial neural networks. The proposed models' importance is reflected in the clear indicators for enforcing the stricter occupational safety and organizational measures in order to reduce the number of work-related injuries in underground mines.
\end{abstract}

Keywords: mining industry, safety, work-related injuries, artificial neural networks

\section{INTRODUCTION}

Research in the area of the work-related injuries, conducted so far, clearly point to the fact that some of the causes of injuries are more frequent than the others and that, based on frequency of their appearance, certain groups of injuries can be singled out. In creating the model for the work-related injuries analysis and prediction, one has to find the right combination of the influential factors and causes that are contributing to 
workers being injured. The injuries prediction has a complex structure, since appearance of an injury can be influenced by a completely subjective situation that happened to the worker on the way to work and because of which he was not concentrated enough that day. During the study of the work-related injuries in the mining industry one has to take into account all the available data from as many sources as possible and discover the hidden risks like the social, psychological etc.

The objective of this research was to define causes of injuries and single out the most important factors, to be able to formulate the input data for the model of the work-related injuries. The problem appears in defining the adequate set of the input data on the nature of workers' injuries. This is a multifold complex problem. The outcome of the injury is being influenced, to the great extent, by some generally know transparent factors, like worker's age, sex, work experience, organization, working environment, duration of exposure to a potentially risky situation, as well as some less transparent factors, like the social, mental and even cultural parameters.

If one considers the prediction from the aspect of predicting the events that are potentially dangerous to safety and health of the employee, it is becoming especially important, since the work-related injuries prevention is a priority in any company's business. In analysis of the work-related injuries, majority of employers rely on expert opinions of persons in charge of the occupational safety and on analysis of the statistical data. The expert opinions obviously have an important role in evaluating the occupational safety, however, they are almost always subjective and caused by previous experiences. The objective approach in the work-related injuries is provided by the machine learning techniques. Vallmuur (2015) reports in his study that the machine learning techniques are widely applied for analysis of injuries, namely $46 \%$ of them are analyzing the work-related injuries. Many researchers point to advantages in using these techniques for predicting the work-related injuries events.

Many studies were involved in analysis of injuries with help of the artificial neural networks (ANN) and compared the success rate in predicting injuries by this method to results of other methods. Stylianou et al. (2015) have compared success rate of predicting the mortality rate of patients that suffered burns by methods of the logistic regression and machine learning. They used several techniques, one of which was the ANN method. The neural networks have been singled out as the most precise method for prediction of the mortality rate. Sarkar et al. (2018) used the two methods of the machine learning, the artificial neural networks and the Support Vector Machine (SVM). Both methods were very successful in predicting the outcome of the work-related injuries in the Indian steel industry. The SVM with $90.67 \%$ was slightly more successful that the ANN method with $89.33 \%$ success rate. Rivas et al. (2011) have also studied the work-related injuries and they used the logistic regression method as well as the data mining (decision rules, classification trees and Bayesian networks). All the techniques had approximately similar results. Their success rate was very high, it was $88.71 \%$ for the most successful Bayesian networks, while for the logistic regression method it was $72.58 \%$. Delen et al. (2006) performed an analysis of the traffic-related injuries and created eight models of the artificial neural networks of the same structure and same input data with different combinations of the outputs. The output variables described the possibility of events (five possible events - from no injury to fatal injury). It was established that such models with combination of outputs represent the outputs much more precisely than the single model with all the five outputs. Ciarapica and Giacchetta (2009) have used the ANNs and fuzzy conclusions (Sugeno's Fuzzy 
Inference System - FIS) to predict the number and severity of injuries. For the modeling they used the data base on injuries that occurred in the construction industry in Italy. This industry is, according to numbers and severity of injuries, similar to the mining industry. Accuracy of prediction, based on the number of injuries, was $86.2 \%$ for the ANN and $90.15 \%$ for the FIS model, while the accuracy of the injuries' severity was $91.3 \%$ for the ANN and $93.5 \%$ for the FIS. However, in investigation by Chena and Luoa (2016), of injuries in the construction industry, resulting from falls from a height, the ANN model gave an extremely low accuracy of $49 \%$ for prediction of severity of injuries.

As one can conclude from the above, most of the ANN models have shown the high accuracy in prediction of the work-related injuries (over $80 \%$ ).

\section{WORK-RELATED INJURIES PREDICTION BY NEURAL NETWORKS}

Danger of injuries in the mining industry is being considered through influences related to worker's environment, working hours, workplace, years of work experience. Difficult working conditions in underground mines, especially in the underground exploitation of coal, are reflected in the presence of the heavy physical - manual work, physiologically unfavorable position of the workers' bodies considering the very narrow space in which they work. In addition, there is a presence of the transporting machines with large number of the rotating parts, which in the poor visibility and limited space conditions can endanger the miners during the moving, manipulation or cleaning those machines. Another specificity of the underground exploitation is a possibility of the sudden collapse of the rock mass and occurrence of the mountain strikes, penetration of water and liquid materials. What certainly distinguishes mining in relation to other activities are collective accidents, a large number of fatal injuries and a large number of injuries at work with respect to the number of workers.

In order to define the input data for the neural network, a survey was conducted in all the mines of the underground coal exploitation in Serbia. Total of 1300 respondents were surveyed; the total number of workers in this sector is 4500 . After analyzing the data, 118 questionnaires were discarded as incomplete, while 1182 were kept.

\subsection{Analysis and review of data from questionnaires}

Data obtained through the survey were analyzed by the descriptive statistics method, presented in the following.

Figure 1 presents the diagram of workers that did or did not suffer an injury in their career so far, by production units, i.e. mines. The number of workers who had suffered injuries is marked in red, total of 298 , while the number of workers without injuries is marked in green, total of 884 .

The same color coding - red for yes (had injuries) and green (no injuries) is followed in all the presented diagrams.

Analysis of Figure 1 data shows that the largest number of surveyed workers is in the "Ibarski rudnici" mine, 266, out of which $17.7 \%$ (47) were injured. Observing the ratio of workers who did or did not experience an injury, the most unfavorable ratio is in the "Sokobanja" mine, where the number of workers who experienced injury is $46.1 \%$, i.e. almost half of the workers. A similar unfavorable situation is in the "Senjski rudnik" mine, where a total of $42.6 \%$ of respondents suffered an injury. These results lead to the conclusion that a larger number of injuries occur in these mines than in the others. 
Figure 2 shows the number of workers who did or did not experience an injury according to their age. It is an interesting fact that among the oldest population, which is represented by only 20 respondents, there was no a single worker who was interviewed that had suffered an injury. This can be explained by the fact that in Serbia, workers who work in riskier jobs where injuries are more frequent, have a beneficial working age, i.e. the right to retire at the age of 56. Thus, the surveyed sample includes workers who work in less risky jobs, i.e. those who are not yet retired.

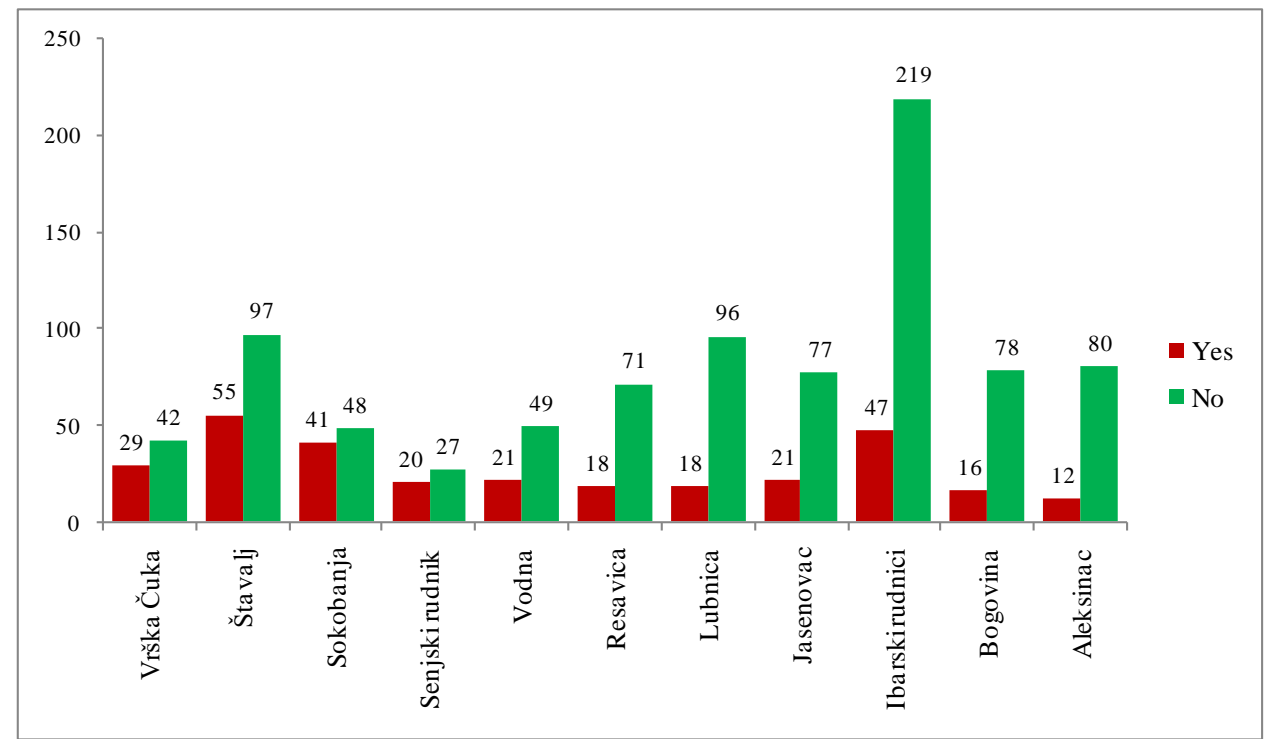

Fig. 1. Graphical presentation of surveyed workers who had/had not suffered an injury according to the production units or mines

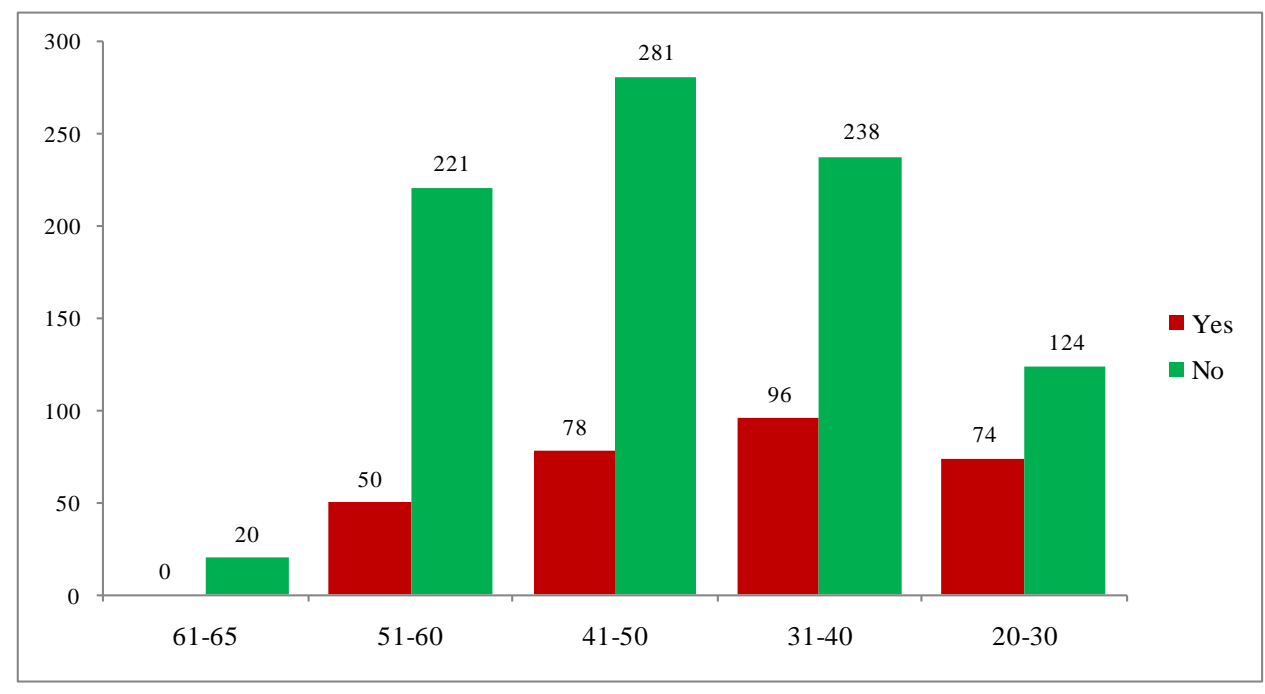

Fig. 2. Graphical presentation of surveyed workers who had/had not suffered an injury according to their age

Figure 2 shows that the highest percentage of workers who have suffered an injury in the last 5 years is in the category of workers aged $31-40$ and that is $32.2 \%$. After that, is the category $41-50(26.2 \%)$ and then the younger population $20-30(24.8 \%)$. This category also has the smallest difference between respondents who did/did not experience an injury. The ratio is $62.6 \%$ of respondents without injury to $37.4 \%$ with 
injury, which indicates that a large number of newly hired workers are injured in the mine primarily due to lack of experience.

Figure 3 shows the number of workers who did or did not suffer an injury according to their working age. Data presented in Figures 2 and 3 are usually corresponding to each other, since it is expected that the younger workers have less working experience, which does not have to be the rule. In the seventies and eighties of the twentieth century very young workers started to work in mines, who then had a large working experience and still remained in the category of young. Therefore, in category with over 36 years of working age there is $18.9 \%$ of total of the surveyed workers. Thus, one can see that 31 workers at the age of 51 to 60 suffered an injury. This is a category of workers that are about to retire and it is noticed that close to the end of the working age, workers are more prone to injuries, out of which the most frequent cause is slipping.

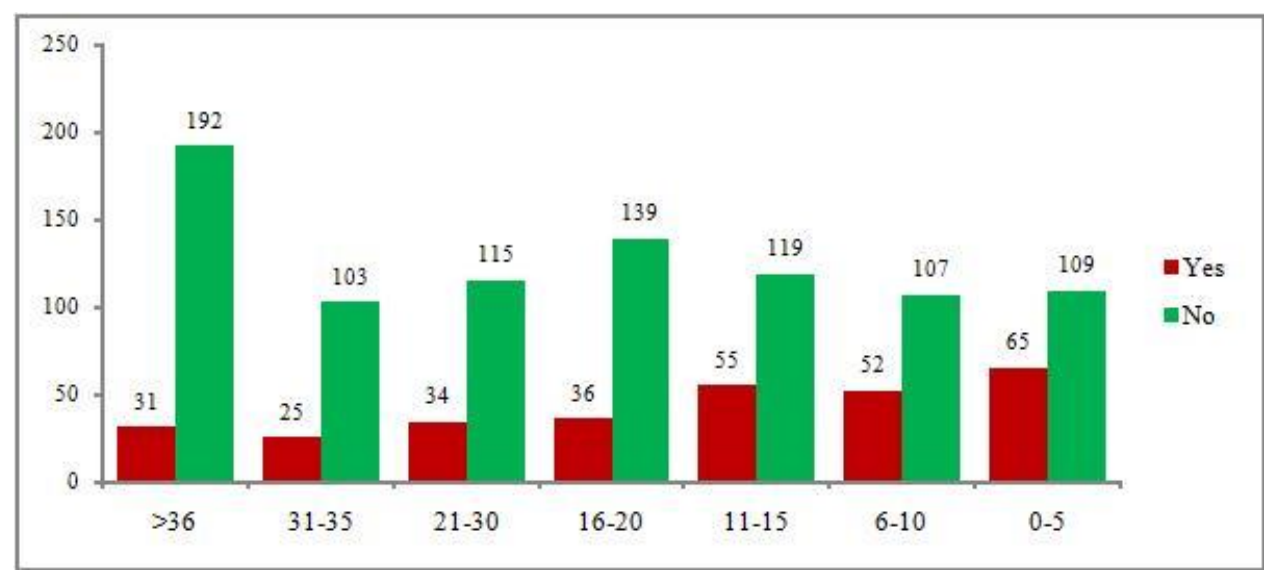

Fig. 3. Graphical presentation of surveyed workers who had/had not suffered an injury according to years of the working age

In Figure 4 is presented a number workers who did or did not suffer an injury according to their professional qualifications.

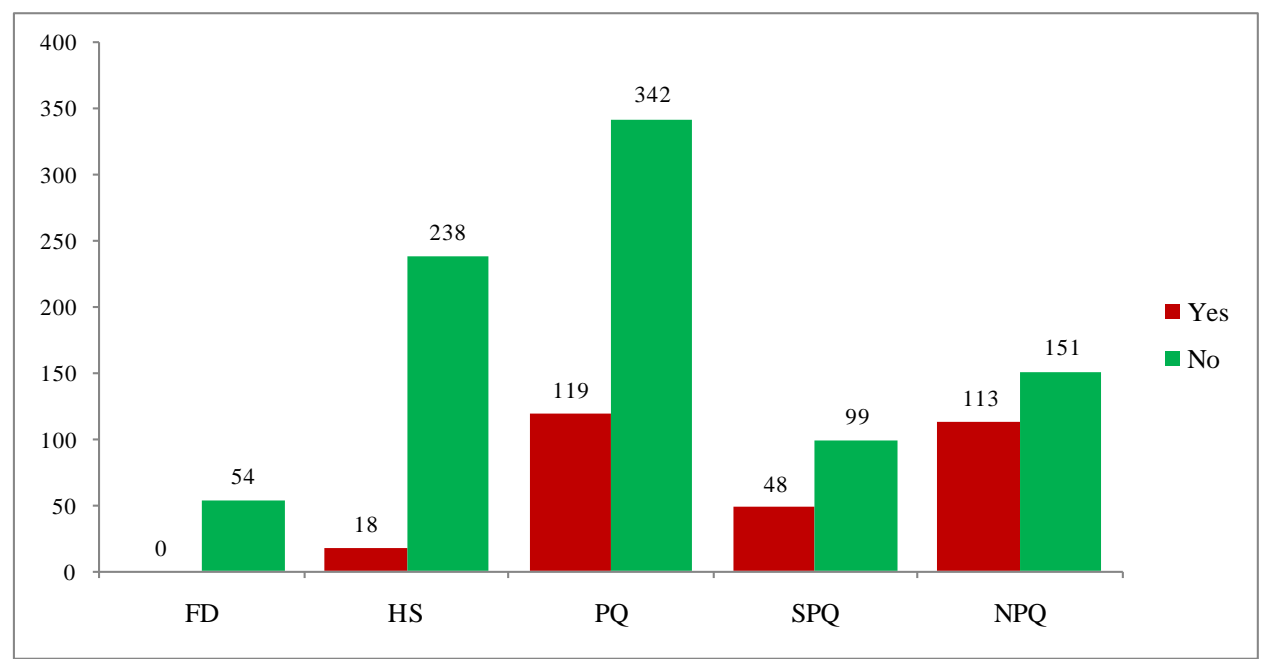

Fig. 4. Graphical presentation of surveyed workers who had/had not suffered an injury according to their professional qualifications. FD - faculty degree, HS - high school, PQ professional qualification (meaning trained for the job), SPQ - semi-qualified worker, NPQ without professional qualification 
From Figure 4 can be seen that the worst situation with number of injuries is in the category of workers that do not have any professional qualification. The percentage of workers in this category that suffered injuries is $42.8 \%$ and with respect to total number of injuries that is $37.2 \%$. From Figure 4 one can also notice that the percentage of injuries is decreasing with increasing professional qualification of workers.

In Figure 5 is shown a number workers who did or did not suffer an injury according to their working age at the present working place/position.

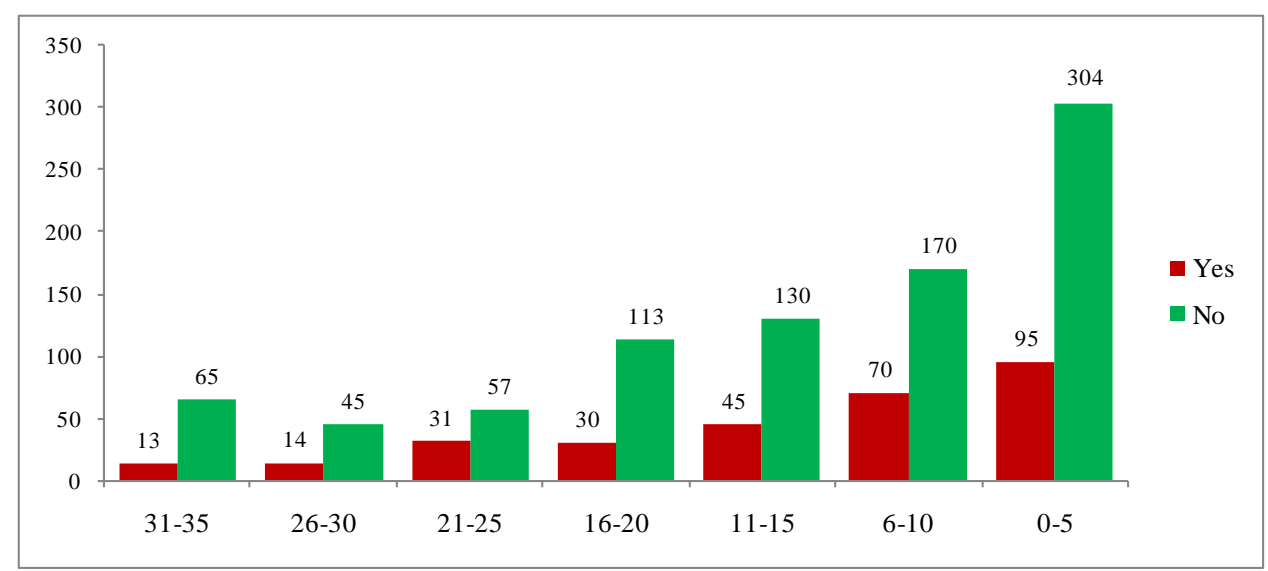

Fig. 5. Graphical presentation of surveyed workers who had/had not suffered an injury according to the working age at the present working position

From Figure 5 one can notice the clear trend that the largest number of injuries occurs to workers who do not have the working experience at the present working position $23.8 \%$ and those with up to 10 years of experience $29.2 \%$. This trend is understandable, considering the difficult working conditions in the underground coal exploitation. The mines should improve the training of workers related to the occupational safety and to introduce more serious and extended programs of training the workers at the beginning of their professional career.

In Figure 6 is shown a number workers who did or did not suffer an injury according to their satisfaction by their wage.

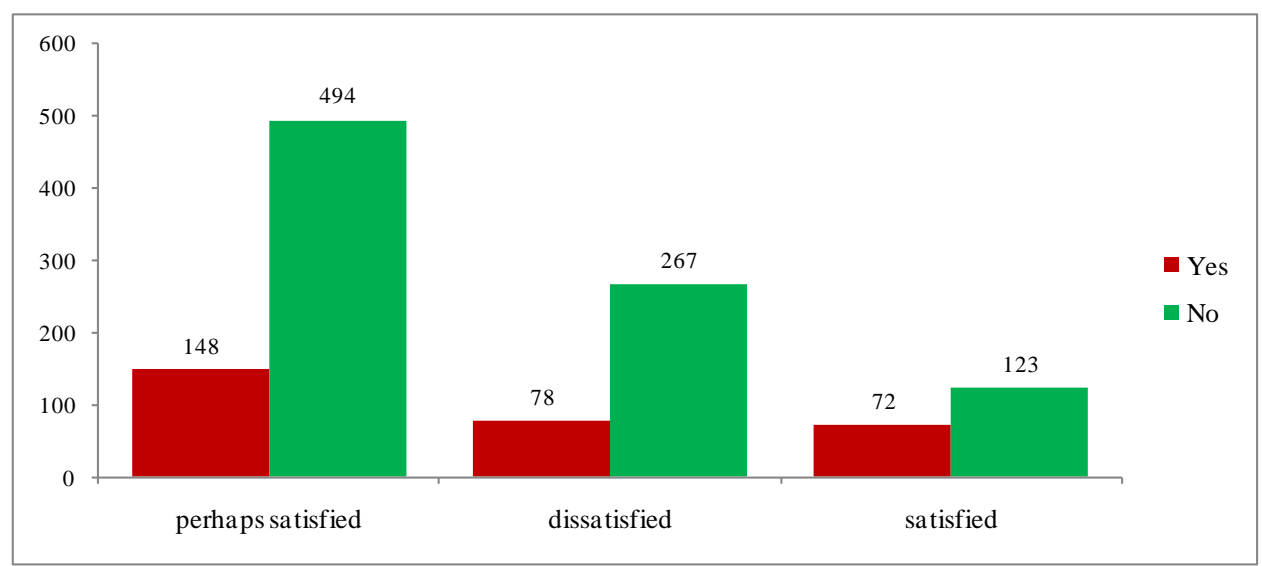

Fig. 6. Graphical presentation of surveyed workers who had/had not suffered an injury according to their satisfaction with the wages

From Figure 6 can be concluded that satisfaction with one's wage does not play a significant role with respect to number of the work-related injuries. The largest number 
of injuries is actually in the category of workers that did not give a decisive answer, i.e. $49.7 \%$.

In Figure 7 is presented a number of workers who did or did not suffer an injury according to their type of the work engagement.

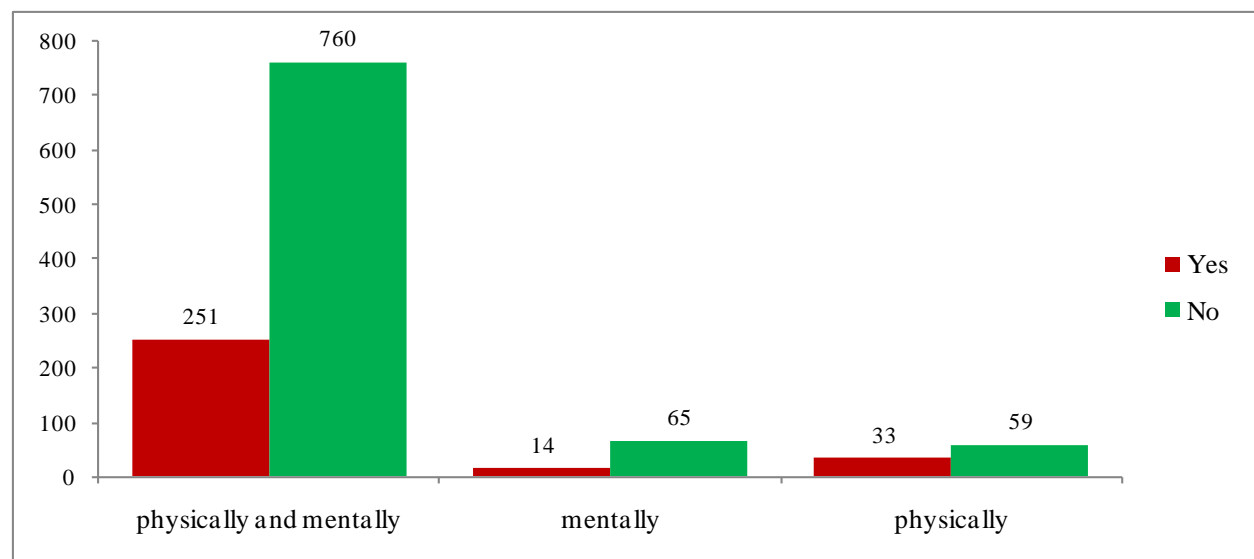

Fig. 7. Graphical presentation of surveyed workers who had/had not suffered an injury according to the type of their working engagement

From Figure 7 can be seen that, same as in the case of the satisfaction with the wage, the clear/decisive results were not obtained. The majority of workers classified their jobs as both physical and mental engagement and that is the category with the largest number of injuries recorded.

In Figure 8 is presented a number of workers who did or did not suffer an injury according to their need for overtime engagement.

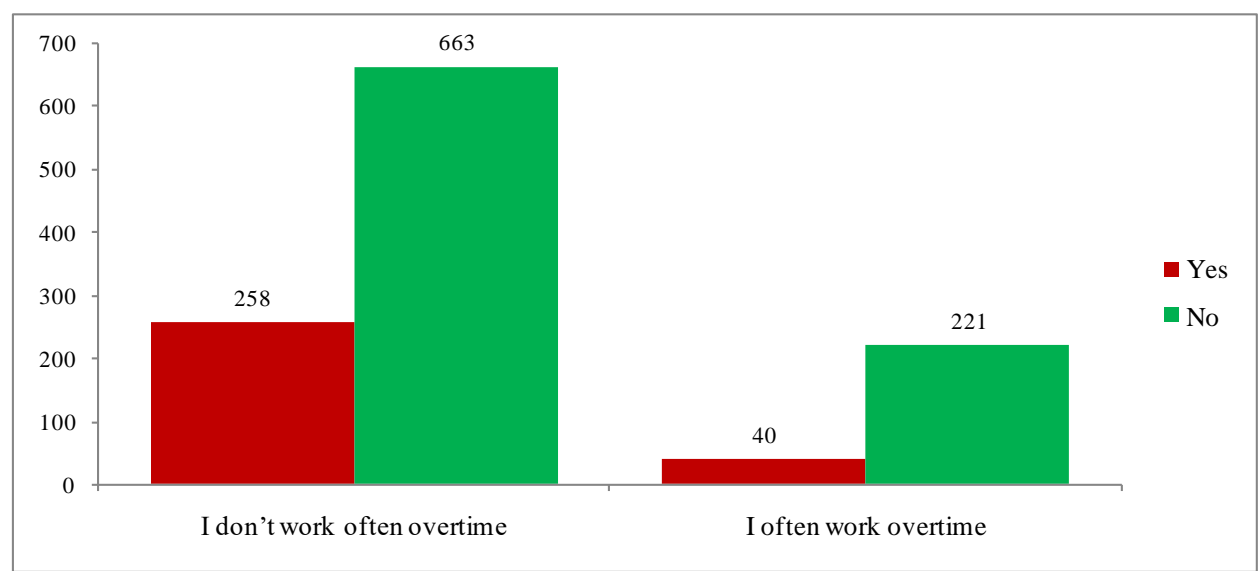

Fig. 8. Graphical presentation of surveyed workers who had/had not suffered an injury according to their overtime engagement

From Figure 8 one can conclude that majority of workers who suffered an injury said that they do not work overtime. Though one could conclude that the overtime engagement, i.e. fatigue and exhaustion, should lead to increased number of injuries, that is not the case in the recorded survey.

In Figure 9 is shown a number of workers who did or did not suffer an injury with respect to workers' satisfaction with the personal protective equipment.

From Figure 9 one can see that in the category of workers that suffered an injury $27.3 \%$ characterized their personal protective equipment as inadequate, while $24.3 \%$ considered it as adequate. 
In Figure 10 is presented a number of workers who did or did not suffer an injury with respect to the protection measures at the working place.

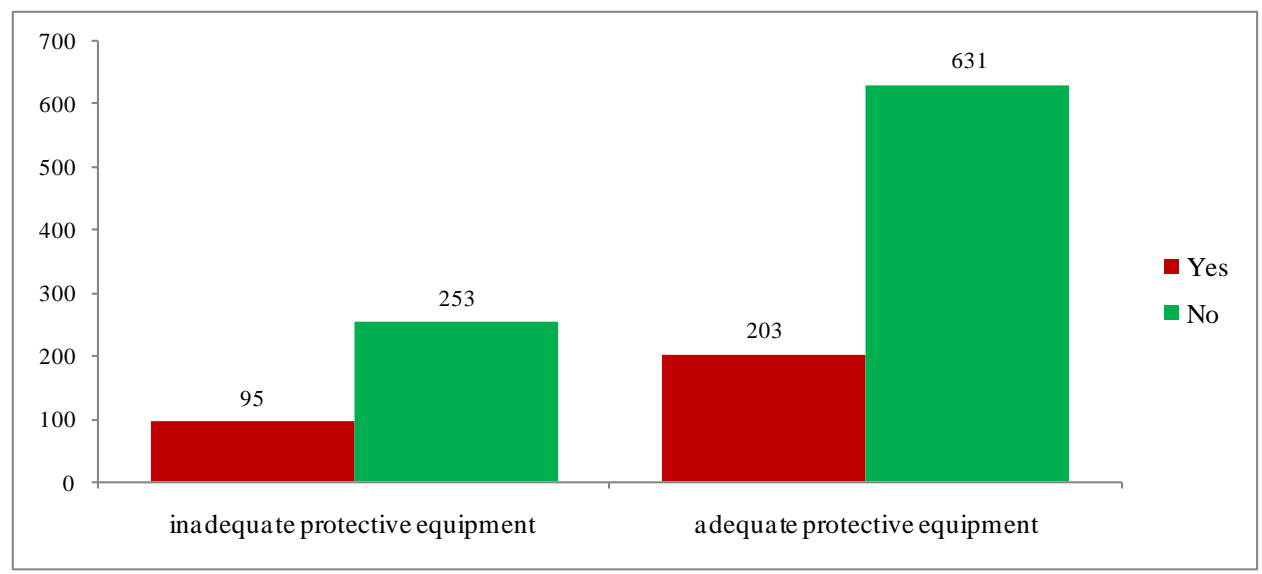

Fig. 9. Graphical presentation of surveyed workers who had/had not suffered an injury according to satisfaction of workers with their personal protective equipment

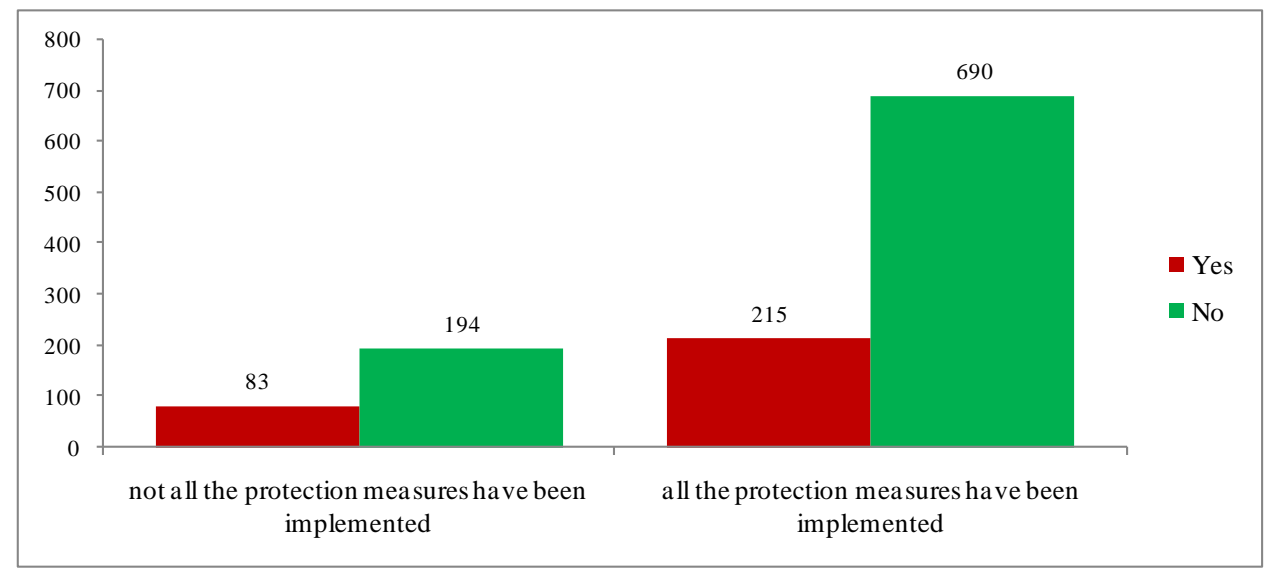

Fig. 10. Graphical presentation of surveyed workers who had/had not suffered an injury according to the implemented protective measures

In Figure 11 is shown number of workers who did or did not suffer an injury according to their understanding whether the occupational safety measures were clearly presented or not.

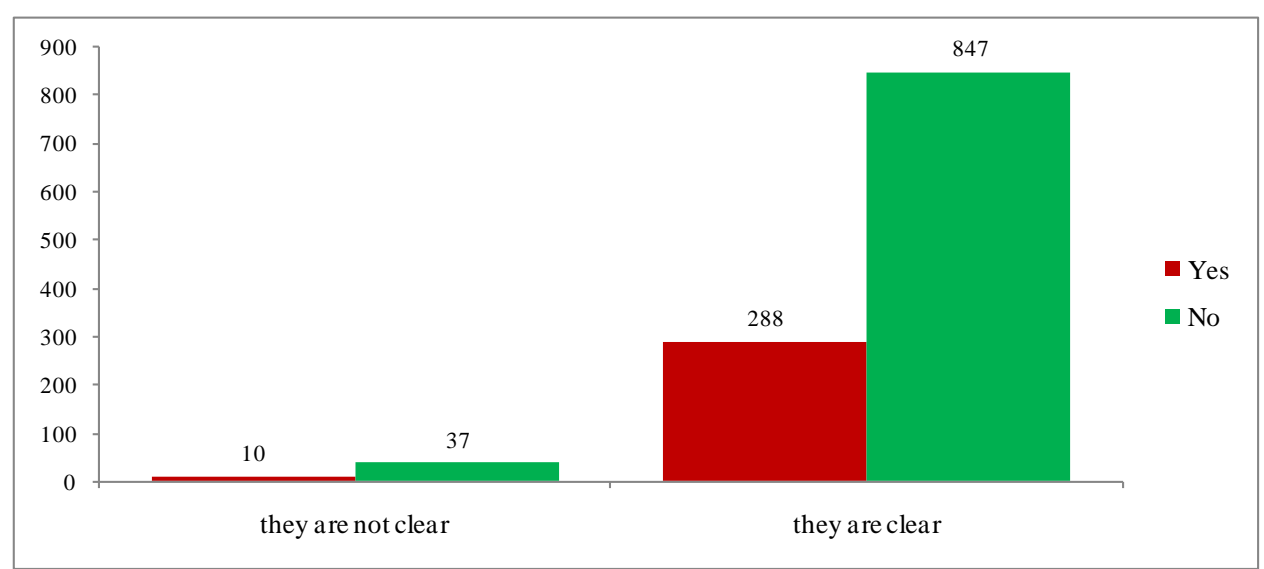

Fig. 11. Graphical presentation of surveyed workers who had/had not suffered an injury according to understanding instructions for the occupational safety measures application 
Based on Figures 10 and 11 it can be concluded that to the majority of workers it was clear what the procedures for occupational safety must be followed and that those procedures are adequately presented by the corresponding expert personnel. Here the question arises: If the procedures are clear to workers, why are they not implemented? In Figure 12 is shown a number of workers who did or did not suffer an injury according to duration of exposure to danger or risks.

Exposure to danger at a certain workplace is directly related to worker's qualification. Majority of the less qualified workers spend all the time at workplaces underground, so it is understandable that $71.3 \%$ of workers who had suffer an injury were exposed to danger during the whole work time.

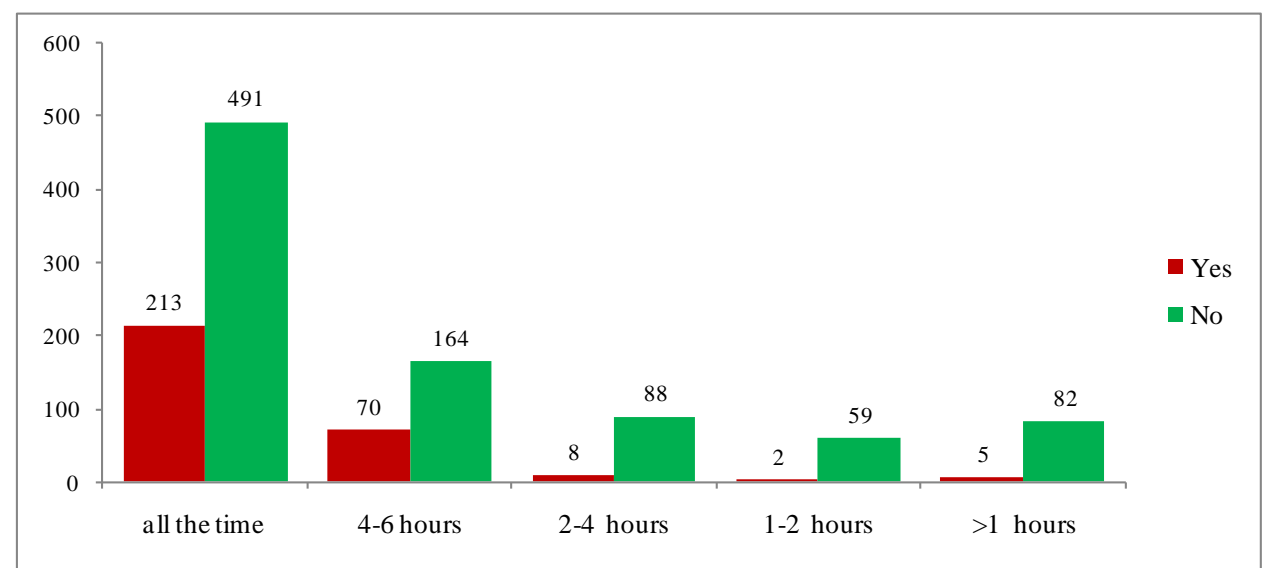

Fig. 12. Graphical presentation of surveyed workers who had/had not suffered an injury according to duration of exposure to danger/risks

In Figure 13 is shown a number of workers who had or had not suffer an injury based on what respecting the protective measures depends.

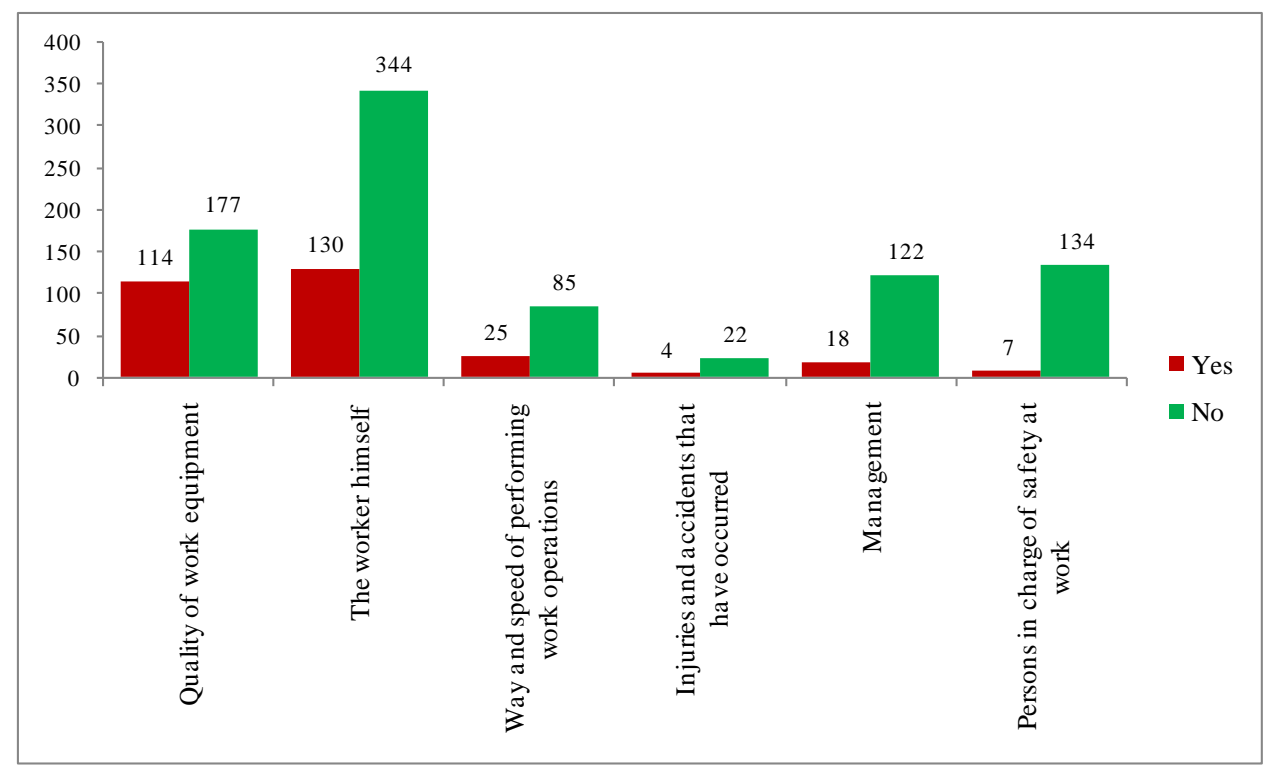

Fig. 13. Graphical presentation of surveyed workers who had/had not suffered an injury based on what respecting of protective measures depends

From Figure 13 one can see that workers' opinions are grouped around the answer: Quality of the work equipment. That testifies about the outdated technology that is 
applied in the coal mines in Serbia. The dependence on the worker himself speaks about the fact that workers are clear about the procedures and aware of importance of the protective measures, but that respecting the given procedures and obeying the protective measures are not at the satisfactory level and that the stricter control must be conducted among the workers in the risky categories.

In Figure 14 is presented a number of workers who had or had not suffer an injury based on the danger to which they are exposed at the workplace.

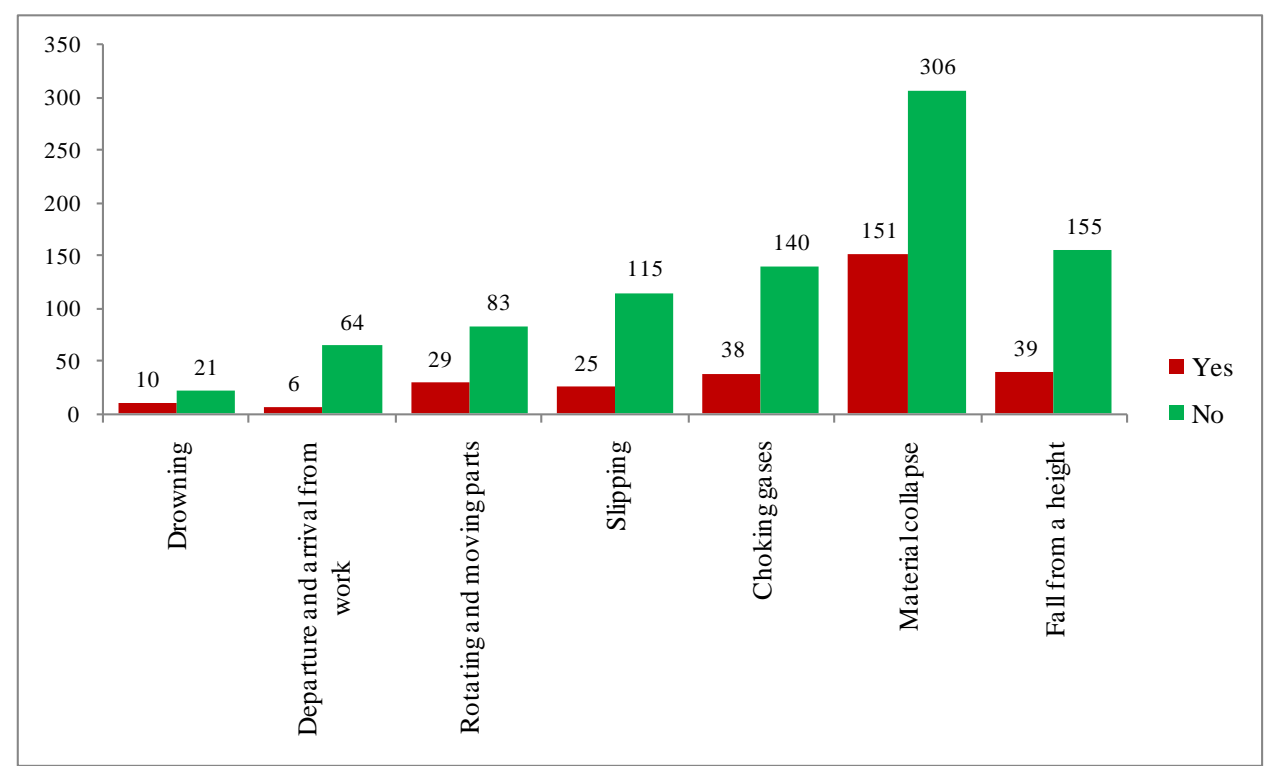

Fig. 14. Graphical presentation of surveyed workers who had/had not suffered an injury according to danger they are exposed to during the work

From Figure 14 one can see that the large number of workers that are working directly at the head of the site are exposed to the danger of collapse in underground exploitation and that a large number of fatal and severe injuries occur due to such a collapse.

\subsection{Application of the neural networks for prediction of the work-related injuries in mining}

Significance of the neural networks is in the fact that they can simultaneously process data, components of which are independent of each other. Many processor units are working simultaneously so that results of their processing could be transferred to the next units (neurons). The processor units in one neural network are simple and can perform only one or eventually a few computational operations. They are interconnected, thus in one neural network exist many more connections than the processor units. Number of these connections between the neurons represents the power of a neural network. The neural networks are used in situations when the rules, according to which it would be possible to relate the input and output data from the desired system, are not known.

The neural networks are not being programmed, they are being trained, so it takes a lot of time for their training, before they can be used. The training is done in such a way that the weight coefficients are being updated, so that the next time the obtained output would be closer to the set value. When the training is completed, the weighing coefficients remain the same and the network can be applied for the intended task. 
The training consists of the user prescribing the input and output values, while the program is trying to get the adequate output value. In doing so, the program initially makes certain mistakes, the difference between the obtained and set output value is being reduced by corresponding change of the weighing parameters.

In this paper, for prediction of the work-related injuries are used the Multilayer Perceptron (MLP) and Radial Basis Function (RBF) neural networks, Table 1.

Table 1

Neural networks' characteristics used for prediction

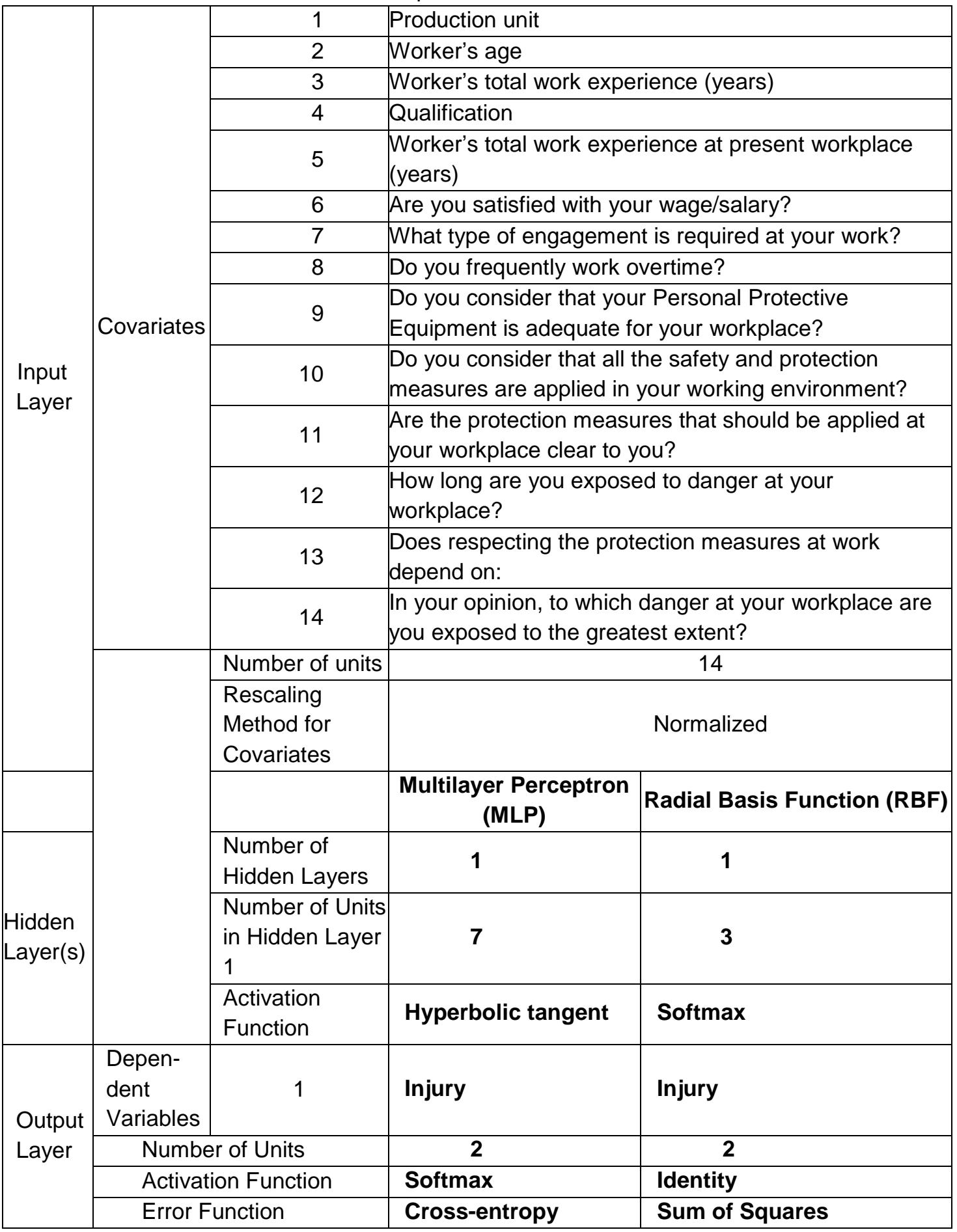


The Multilayer Perceptron is one of the most widely applied neural networks. In this network the training is performed by the Back-propagation algorithm. The Radial Basis Function is a neural network with a radial function, which is also used for solving the prediction problems; however, with respect to the MP it overcomes the problem of a slow training.

In predicting by applying the Multilayer Perceptron, the problem is defined in the following way: based on 14 input variables one predicts whether the surveyed worker has suffered an injury or not. Based on the said, the network has 14 input variables and one output. In the considered example, $70 \%$ of cases are used for training of the network, while $30 \%$ are used for its testing. The network architecture is generated automatically. The network contains one hidden layer and 7 neurons within it.

As can be seen in Table 1, the network is automatically generated, the MLP network has 1 hidden layer and 7 neurons, the activation function is hyperbolic tangent. In the RBF network there is 1 hidden layer and 3 neurons within it.

In Figure 15 is shown appearance of both network models with described architectures. As can be seen from the Figure appearances of the two networks are very different.

Accuracy of the two applied networks can be deduced from Table 2. One can see that the MLP network has higher accuracy both in the training and testing data, $80.4 \%$ and $79.7 \%$, respectively, with respect to the RBF network's accuracy for the training and the testing data is $79.8 \%$ and $77.9 \%$, respectively.

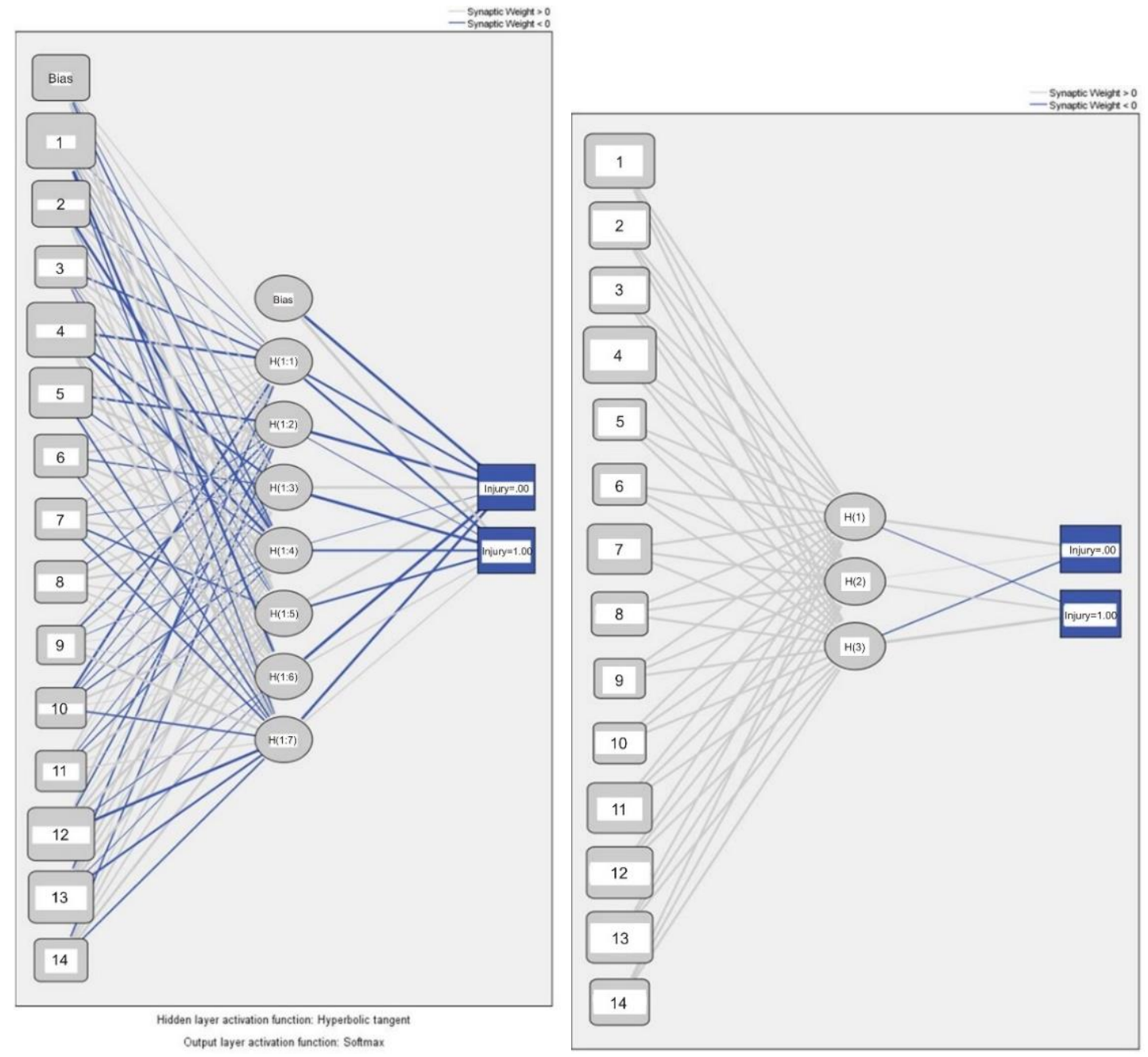

Fig. 15. Appearance of the two network models, MLP (left) and RBF (right) 
From Table 2 can be seen that both networks exhibit lower accuracy when classifying the answer "YES" (the worker did suffer injury), while for the answer "NO" the accuracy is satisfying.

In predicting the work-related injuries in mining the MLP network shows smaller error and it amounts to $20.3 \%$ of all the wrongly classified answers. In addition, the MLP network shows the smaller number of wrongly classified "YES" answers - 109, while this number for the RBF network is 136 .

Table 2

Classification of data within the network

\begin{tabular}{|l|l|l|l|l|l|l|l|}
\hline & & \multicolumn{3}{|c|}{ MLP } & \multicolumn{3}{l|}{ RBF } \\
\hline \multirow{3}{*}{ Sample } & \multirow{3}{*}{ Observed } & \multicolumn{5}{|c|}{ Predicted } & \multicolumn{2}{l|}{ Predicted } \\
\cline { 3 - 9 } & YES & NO & $\begin{array}{l}\text { Accurate } \\
(\%)\end{array}$ & YES & NO & Accurate (\%) \\
\hline \multirow{3}{*}{$\begin{array}{l}\text { Trainin } \\
\text { g }\end{array}$} & YES & $\mathbf{9 7}$ & 109 & 47.1 & $\mathbf{6 4}$ & 136 & 32.0 \\
\cline { 2 - 9 } & NO & 53 & $\mathbf{5 6 8}$ & 91.5 & 28 & $\mathbf{5 8 3}$ & 95.4 \\
\cline { 2 - 9 } & $\begin{array}{l}\text { Overall } \\
\text { Percent }\end{array}$ & $18.1 \%$ & $81.9 \%$ & $\mathbf{8 0 . 4}$ & $11.3 \%$ & $88.7 \%$ & $\mathbf{7 9 . 8}$ \\
\hline \multirow{4}{*}{ Testing } & YES & $\mathbf{4 1}$ & 51 & 44.6 & $\mathbf{3 3}$ & 65 & 33.7 \\
\cline { 2 - 8 } & NO & 21 & 242 & 92.0 & 17 & $\mathbf{2 5 6}$ & 93.8 \\
\cline { 2 - 8 } & $\begin{array}{l}\text { Overall } \\
\text { Percent }\end{array}$ & $17.5 \%$ & $82.5 \%$ & $\mathbf{7 9 . 7}$ & $13.5 \%$ & $86.5 \%$ & $\mathbf{7 7 . 9}$ \\
\hline
\end{tabular}

\subsection{The sensitivity analysis}

The sensitivity analysis represents a technique of determination of the independent variables' influence to a certain dependent variable, for the given circumstances. In the considered case that means the input variables influence on the output variable (whether the worker did or did not suffer an injury). Table 3 presents value of influence for 14 input variables to a single output variable.

Figure 16 shows the graphical presentation of the sensitivity analysis results for both considered network models for 14 input variables.

As can be seen from Figure 16, both networks singled out four common inputs as the most influential on the output result, those being the answers to the following four questions:

1. Production unit (or mine)

2. Qualification

3. How long are you exposed to danger at your workplace?

4. Does respecting the protection measures at work depend on:

- Persons in charge of the occupational safety

- Management

- Injuries and accidents that have occurred

- Way and speed of performing the work operations

- The worker himself

- Quality of the work equipment?

The workers' qualifications being singled out by the neural networks is an assumption reached by other authors, as well, Stojadinović et al. (2012), Karra (2005), Sari et al. (2004) by different methods. 
Qualification, in combination with the workplace, has a great influence on injury occurrence, primarily because it influences duration of exposure to some danger, causes the type of the work environment and defines jobs that the worker is performing, as well as on which machines and dangers of the tools to which he could be exposed. Besides that, the low level of education also affects understanding of the safety procedures, instructions, training, restrictions etc.

One can also say that the three following highly ranked inputs are related to qualification - each production unit or mine (the second ranked input) where the worker is employed creates its own safety politics, while exposure to certain danger is directly related to the workplace, i.e. qualification.

Table 3

Independent Variables Importance

\begin{tabular}{|l|l|l|l|l|}
\hline & \multicolumn{2}{|c|}{ MLP } & \multicolumn{2}{c|}{ RBF } \\
\hline Importance & $\begin{array}{l}\text { Normalized } \\
\text { Importance, } \\
\%\end{array}$ & $\begin{array}{l}\text { Importance } \\
\text { Importance, } \\
\%\end{array}$ \\
\hline Production unit (or mine) & .142 & $\mathbf{7 6 . 4}$ & .126 & $\mathbf{8 8 . 4}$ \\
\hline Worker's age & .004 & 2.3 & .069 & 48.7 \\
\hline $\begin{array}{l}\text { Worker's total work experience } \\
\text { (years) }\end{array}$ & .066 & 35.4 & .064 & 45.2 \\
\hline Qualification & .186 & $\mathbf{1 0 0 . 0}$ & .142 & $\mathbf{1 0 0 . 0}$ \\
\hline $\begin{array}{l}\text { Worker's total work experience at } \\
\text { present workplace (years) }\end{array}$ & .087 & 46.8 & .026 & 18.1 \\
\hline Are you satisfied with your wage? & .045 & 24.3 & .029 & 20.6 \\
\hline $\begin{array}{l}\text { What type of engagement is } \\
\text { required at your work? }\end{array}$ & .031 & 16.5 & .092 & 64.7 \\
\hline Do you frequently work overtime? & .041 & 22.2 & .046 & 32.1 \\
\hline $\begin{array}{l}\text { Do you consider that your Personal } \\
\text { Protective Equipment is adequate } \\
\text { for your workplace? }\end{array}$ & .033 & 17.9 & .016 & 11.1 \\
\hline $\begin{array}{l}\text { Do you consider that all the safety } \\
\text { and protection measures are } \\
\text { applied in your working } \\
\text { environment? }\end{array}$ & .044 & 23.4 & .024 & 17.0 \\
\hline $\begin{array}{l}\text { Are the protection measures that } \\
\text { should be applied at your workplace } \\
\text { clear to you? }\end{array}$ & .046 & 25.0 & .095 & 66.4 \\
\hline $\begin{array}{l}\text { How long are you exposed to } \\
\text { danger at your workplace? }\end{array}$ & .126 & $\mathbf{6 7 . 6}$ & .104 & $\mathbf{7 2 . 9}$ \\
\hline $\begin{array}{l}\text { Does respecting the protection } \\
\text { measures at work depend on: ... }\end{array}$ & .126 & $\mathbf{6 7 . 9}$ & .104 & $\mathbf{7 3 . 0}$ \\
\hline $\begin{array}{l}\text { In your opinion, to which danger at } \\
\text { your workplace are you exposed to } \\
\text { the greatest extent? }\end{array}$ & .022 & 12.1 & .063 & 43.9 \\
\hline
\end{tabular}

The third ranked input, the question "Does following the occupational safety measures depends on: Persons in charge of the occupational safety, Management, Injuries and accidents that have occurred, Way and speed of performing the work operations, The worker himself, Quality of the work equipment?" is closely related to worker's 
awareness as an individual and his/her attitude towards the occupational safety as well as to responsibility in performing the everyday work operations, Figure 13.

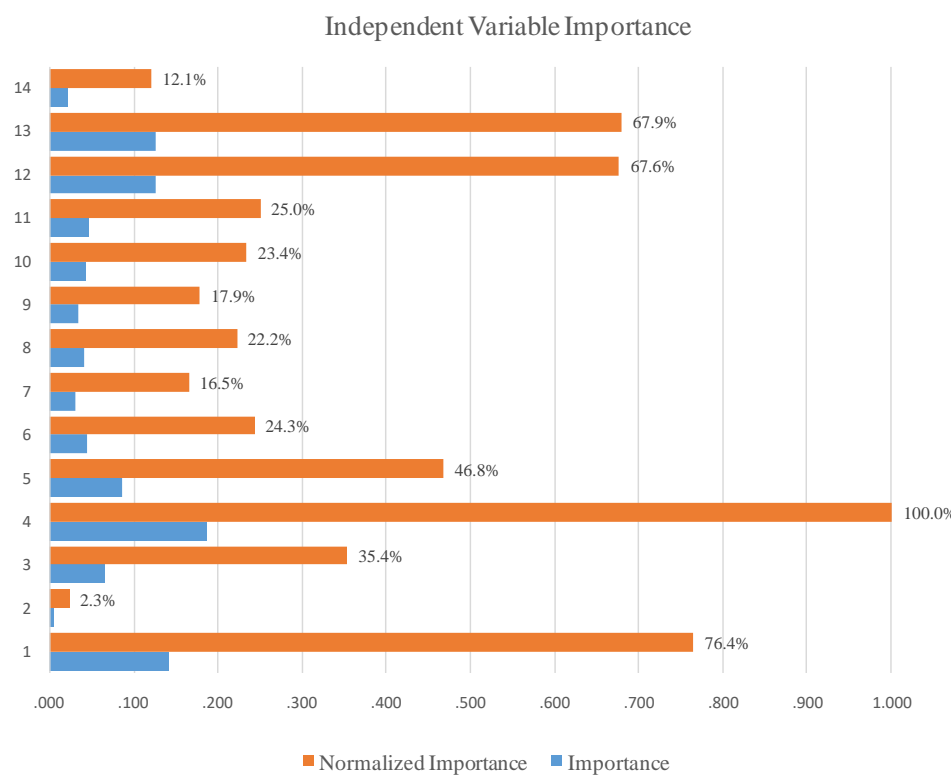

Independent Variable Importance

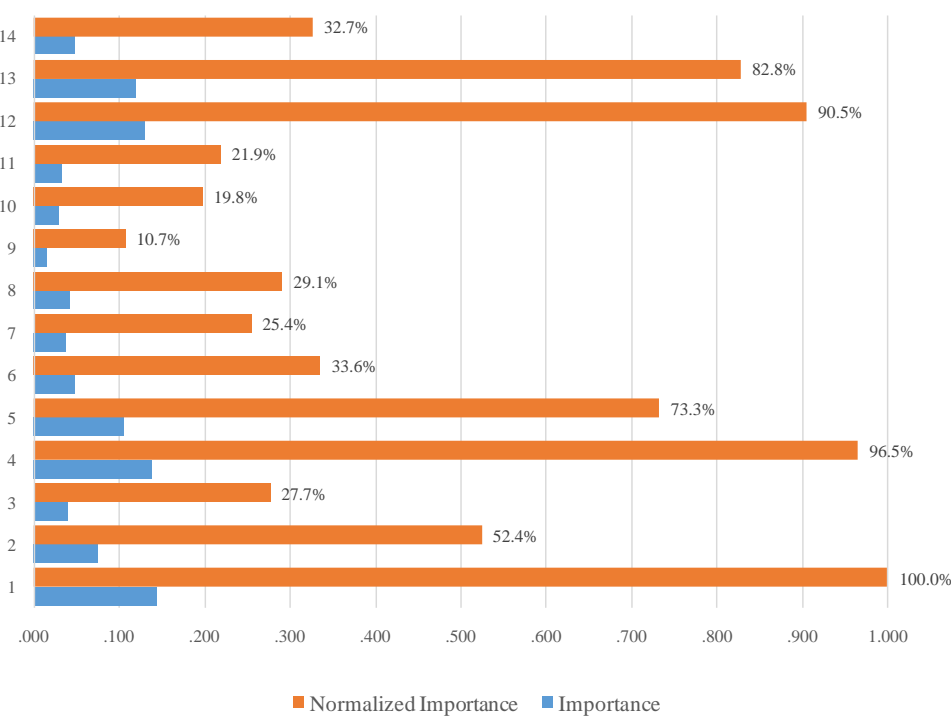

Fig. 16. Graphical presentation of the sensitivity analysis results for both considered network models MLP (top) and RBF (bottom)

\section{ANALYSIS OF RESULTS}

After analysis of results obtained by the sensitivity analysis of the input parameters, the two new neural network models were constructed, the MLP/1 and the RBF/1, Figure 17. The same architecture was used for both networks as in the previous analysis, the difference is in the input data, which are now 4 for each network.

Using the four first ranked inputs as the new input data, the following results are obtained, with respect to accuracy of the output prediction.

The first model is MLP/1. Comparing to the previously described MLP model with 14 input variables, this model exhibits higher accuracy of the data prediction. Its error amounts to $18.95 \%$ and accuracy is over $80 \%$, Table 4 . 

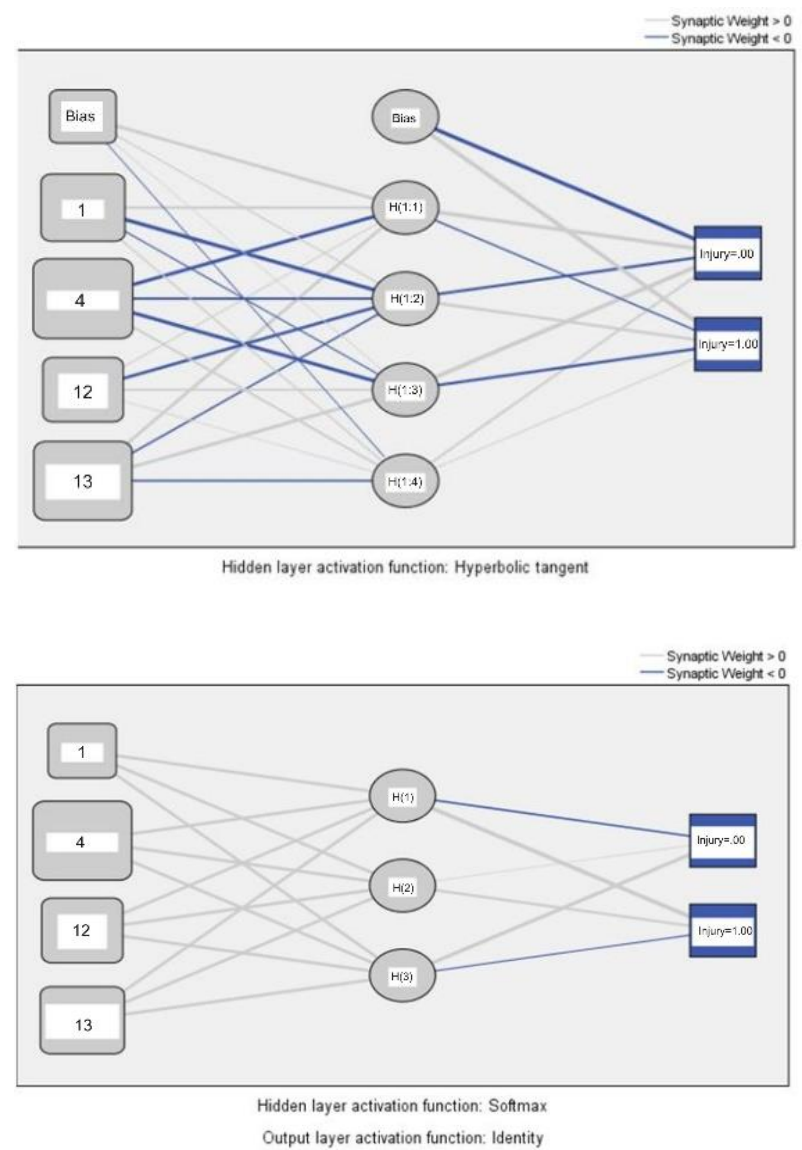

Fig. 17. Appearance of the new network models, MLP/1 (top) and RBF/1 (bottom)

Table 4

Characteristics and accuracy of the neural network model MLP/1

\begin{tabular}{|c|c|c|c|c|}
\hline \multicolumn{5}{|c|}{ Model Summary } \\
\hline \multirow{4}{*}{ Training } & Cross Entropy Error & \multicolumn{3}{|c|}{355.897} \\
\hline & $\begin{array}{l}\text { Percent of Incorrect } \\
\text { Predictions, \% }\end{array}$ & \multicolumn{3}{|l|}{19.8} \\
\hline & Stopping Rule Used & \multicolumn{3}{|c|}{$\begin{array}{l}1 \text { consecutive step(s) with no } \\
\text { decrease in error }\end{array}$} \\
\hline & Training Time & \multicolumn{3}{|c|}{ 0:00:00.133 } \\
\hline \multirow[b]{2}{*}{ Testing } & Cross Entropy Error & \multicolumn{3}{|c|}{135.459} \\
\hline & $\begin{array}{l}\text { Percent of Incorrect } \\
\text { Predictions, \% }\end{array}$ & \multicolumn{3}{|l|}{18.1} \\
\hline \multicolumn{5}{|c|}{ Classification } \\
\hline \multirow[b]{2}{*}{ Sample } & \multirow[b]{2}{*}{ Observed } & \multicolumn{3}{|c|}{ Predicted } \\
\hline & & YES & NO & $\begin{array}{l}\text { Percent } \\
\text { Correct\% }\end{array}$ \\
\hline \multirow{3}{*}{ Training } & YES & 96 & 132 & 42.1 \\
\hline & $\mathrm{NO}$ & 36 & 586 & 94.2 \\
\hline & Overall Percent, \% & 15.5 & 84.5 & 80.2 \\
\hline \multirow{3}{*}{ Testing } & YES & 32 & 38 & 45.7 \\
\hline & NO & 22 & 240 & 91.6 \\
\hline & Overall Percent, \% & 16.3 & 83.7 & 81.9 \\
\hline
\end{tabular}


Besides an increase in the model's total accuracy, the model still exhibits not so high accuracy in predicting the "YES" answer with $42.1 \%$ for the training data set and $45.7 \%$ for the testing data set. From that aspect, this network has inappropriate performance since it is of the much greater importance to properly categorize the event: "Yes, there is an injury or The injury did occur", i.e. to recognize the answer "Yes".

From Figure 18 one can also notice that at the MLP/1 model the ranking order of the input parameters is changed and that now Qualification is singled out as the most important parameter. The second most important parameter is "Does following the occupational safety measures depends on: Persons in charge of the occupational safety, Management, Injuries and accidents that have occurred, Way and speed of performing the work operations, The worker himself, Quality of the work equipment?" The work unit or mine is at the third place.

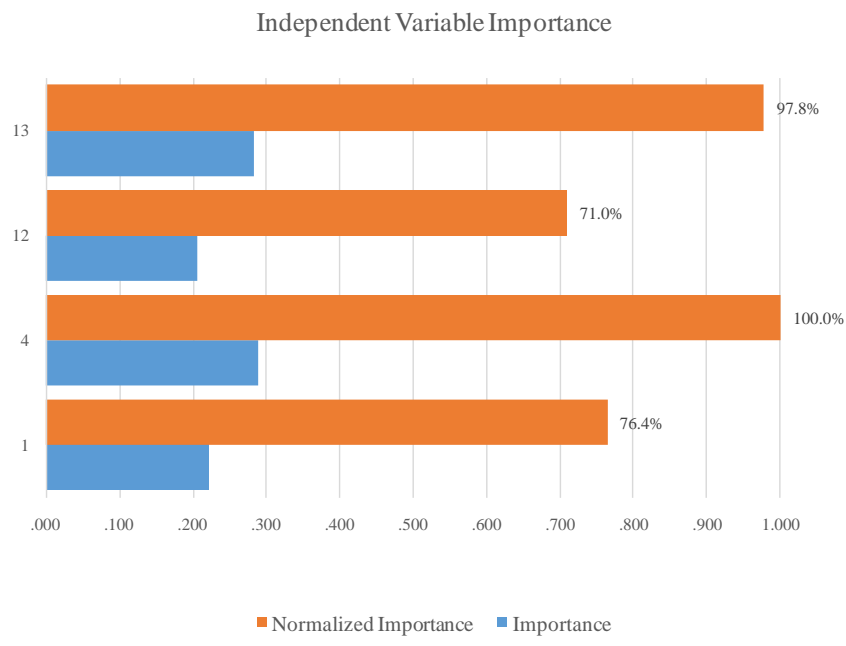

Fig. 18. Ranking of the input parameters influence on the output for the MLP/1 model

The second model RBF/1 exhibits the lower error of $18.55 \%$ with respect to the first RBF model and with respect to both other models, MLP and MLP/1, as well, Table 5.

Table 5. Characteristics and accuracy of the neural network model RBF/1

\begin{tabular}{|c|c|c|c|c|}
\hline \multicolumn{5}{|c|}{ Model Summary } \\
\hline \multirow{3}{*}{ Training } & \multicolumn{2}{|l|}{ Sum of Squares Error } & \multicolumn{2}{|c|}{123.781} \\
\hline & \multicolumn{2}{|c|}{ Percent of Incorrect Predictions, \% } & \multicolumn{2}{|c|}{22.0} \\
\hline & \multicolumn{2}{|l|}{ Training Time } & \multicolumn{2}{|c|}{ 0:00:00.392 } \\
\hline \multirow{2}{*}{ Testing } & \multicolumn{2}{|l|}{ Sum of Squares Error } & \multicolumn{2}{|c|}{41.959} \\
\hline & \multicolumn{2}{|c|}{ Percent of Incorrect Predictions, \% } & \multicolumn{2}{|c|}{15.1} \\
\hline \multicolumn{5}{|c|}{ Classification } \\
\hline \multirow{2}{*}{ Sample } & \multirow{2}{*}{ Observed } & \multicolumn{3}{|l|}{ Predicted } \\
\hline & & YES & NO & Percent Correct \% \\
\hline \multirow{3}{*}{ Training } & YES & 88 & 129 & 40.6 \\
\hline & NO & 54 & 560 & 91.2 \\
\hline & Overall Percent, \% & 17.1 & 82.9 & 78.0 \\
\hline \multirow{3}{*}{ Testing } & YES & 42 & 39 & 51.9 \\
\hline & NO & 14 & 256 & 94.8 \\
\hline & Overall Percent, \% & 16.0 & 84.0 & 84.9 \\
\hline
\end{tabular}


In Figure 19 can be seen that the ranking order of the input variables influence has changed here, as well. Thus, the most important is qualification of a worker, the second most important input is opinion of a worker, i.e. his/her awarness of occupational safety importance. As can be seen from Figure 13, workers are very aware of the proper way of reasoning, i.e. that the safety is an individual attitude and each of them individually contributes to development and maintaining of the safety policy within the company. A priority should be given to development and strengthening of this attitude, in the underground coal exploitation and through education and other contents to contribute to strengthening of the workers' awareness.

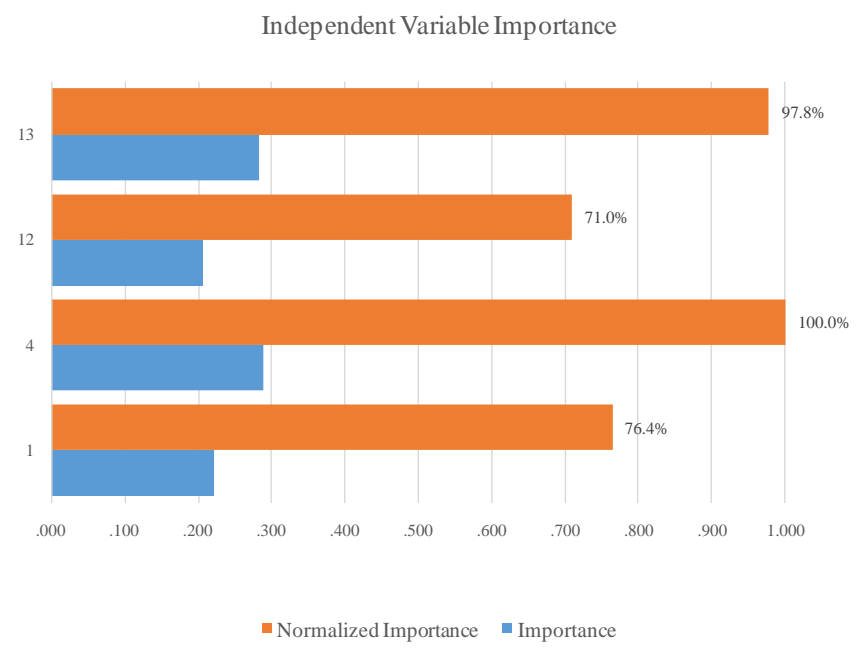

Fig. 19. Ranking of the input parameters influence on the output for the RBF/1 model

Qualification is directly related to the workplace and dangers to which the worker is exposed. Improvement of this problem can be achieved by the strict control and application of the new technologies where the most endangered HS and PQ workers would perform work operations mechanically and reduce the impact of their workplace on the outcome of injuries at work.

From all the above follows that for predicting the work-related injuries in mining the best is to use the RBF/1 neural network architecture, since it provides the best results for accuracy of the output classification.

\section{CONCLUSIONS}

The problem of prediction the work-related injuries in mining is considered in this paper by the neural network modeling. The multilayer perceptron (MLP) and radial basis function (RBF) neural networks were used with 14 input variables. After the sensitivity analysis (of output to individual inputs), the first four ranked inputs were singled out. Those most influential/important variables were then used for forming the new neural network models MLP/1 and RBF/1, accuracy of which was increased by application of this set of input variables. The proposed models represent support in eliminating deficiencies in the occupational safety system. It is necessary to focus the further research to development of the new neural network architectures, to improve their performance.

It is the most favorable to use the RBF/1 neural network architecture for prediction of the work-related injuries in mining, for the described parameters, since it gives the better results in terms of the accuracy of the output classification. 
It can certainly be concluded that such neural network models can be applied to predict injuries at work in the mining industry, as well as to point out to gaps in safety at work in each of the mines and in the underground mining in Serbia, as a whole.

\section{ACKNOWLEDGEMENT}

This research was partially financially supported by the project "Innovative Solutions for Propulsion, Power and Safety Components of Transport Vehicles" ITMS 313011 V334 of the Operational Program Integrated Infrastructure 2014-2020 and co-funded by the European Regional Development Fund and by the Ministry of Education, Science and Technological Development of Republic of Serbia through the funding of the scientific research work at the University of Belgrade, Technical Faculty in Bor, according to contract 451-03-68/2020-14/200131.

\section{REFERENCES}

Chena, H., Luoa, X., 2016. Severity Prediction Models of Falling Risk for Workers et Height. Procedia Engineering, 164, 439-445, DOI: 10.1016/j.proeng.2016.11.642.

Ciarapica, F.E., Giacchetta, G., 2009. Classification and prediction of occupational injury risk using soft computing techniques: An Italian study, Safety Science, 47(1), 36-49, DOI: 10.1016/j.ssci.2008.01.006.

Delen, D., Sharda, R., Bessonov, M., 2005. Identifying significant predictors of injury severity in traffic accidents using a series of artificial neural networks, Accident Analysis and Prevention, 38(3), 434-444, DOI: 10.1016/j.aap.2005.06.024.

Karra, V.K., 2005. Analysis of non-fatal and fatal injury rates for mine operator and contractor employees and the influence of work location, Journal of Safety Research 36(5), 413-421, DOI: 10.1016/j.jsr.2005.08.002.

Rivas, T., Paz, M., Martin, J.E., Matias, J.A., Garcia, J.F., Taboada, J., 2011. Explaining and predicting workplace accidents using data-mining techniques, Reliability Engineering and System Safety 96(7), 739-747, DOI: 10.1016/j.ress. 2011.03.006.

Sari, M., Duzgun, H.S.B., Karpuz, C., Selcuk, A.S., 2004. Accident analysis of two Turkish underground coal mines, Safety Science, 4298, 675-690, DOI: 10.1016/j. ssci.2003.11.002.

Sarkar, S., Vinay, S., Raj, R., Maiti, J., Mitra, P., 2019. Application of optimized machine learning techniques for prediction of occupational accidents, Computers and Operations Research, 106, 210-224, DOI: 10.1016/j.cor.2018.02.021.

Stojadinovic, S., Svrkuta, I., Petrović, D., Denic, M., Pantovic, R., Milić, V., 2012. Mining injuries in Serbian underground coal mines - A 10-year study, Injury 43(12), 20012005, DOI: 10.1016/j.injury.2011.08.018.

Stylianou, N., Akbarov, A., Kontopantelis, E., Buchan, I, Dunn, K.W., 2015. Mortality risk prediction in burn injury: Comparison of logistic regression with machine learning approaches, Burns 41(5), 925-934. DOI: 10.1016/j.burns.2015.03.016.

Vallmuur, K., 2015. Machine learning approaches to analysing textual injury surveillance data: A systematic review, Accident Analysis and Prevention, 79, 41-49.

DOI: 10.1016/j.aap.2015.03.018. 